\title{
MHD Flow of a Hybrid Nano-Fluid in a Triangular Enclosure with Zigzags and an Elliptic Obstacle
}

\author{
Ines Chabani ${ }^{1}$, Fateh Mebarek-Oudina ${ }^{1, *}$ and Abdel Aziz I. Ismail ${ }^{2,3}$ \\ 1 Department of Physics, Faculty of Sciences, University of 20 Août 1955-Skikda, 21000 Skikda, Algeria; \\ fmoudina@gmail.com \\ 2 Mechanical Engineering Department, College of Engineering and Islamic Architecture, Umm Al-Qura \\ University, Makkah P.O. Box 5555, Saudi Arabia; aiismail@uqu.edu.sa \\ 3 Mathematics Department, Faculty of Science, Tanta University, Tanta P.O. Box 31527, Egypt \\ * Correspondence: f.mebarek_oudina@univ-skikda.dz or oudina2003@yahoo.fr; Tel.: +21-366-830-5488
}

Citation: Chabani, I.;

Mebarek-Oudina, F.; Ismail, A.A.I. MHD Flow of a Hybrid Nano-Fluid in a Triangular Enclosure with Zigzags and an Elliptic Obstacle. Micromachines 2022, 13, 224. https: / / doi.org/10.3390/mi13020224

Academic Editors: Hong Li and Beng Kang Tay

Received: 12 January 2022

Accepted: 26 January 2022

Published: 29 January 2022

Publisher's Note: MDPI stays neutral with regard to jurisdictional claims in published maps and institutional affiliations.

Copyright: (c) 2022 by the authors. Licensee MDPI, Basel, Switzerland. This article is an open access article distributed under the terms and conditions of the Creative Commons Attribution (CC BY) license (https:// creativecommons.org/licenses/by/ $4.0 /)$.

\begin{abstract}
The current study uses the multi-physics COMSOL software and the Darcy-BrinkmanForchheimer model with a porosity of $\varepsilon=0.4$ to conduct a numerical study on heat transfer by $\mathrm{Cu}-\mathrm{TiO}_{2} / \mathrm{EG}$ hybrid nano-fluid inside a porous annulus between a zigzagged triangle and different cylinders and under the influence of an inclined magnetic field. The effect of numerous factors is detailed, including Rayleigh number $(103 \leq \mathrm{Ra} \leq 106)$, Hartmann number $(0 \leq \mathrm{Ha} \leq 100)$, volume percent of the nano-fluid $(0.02 \leq \phi \leq 0.08)$, and the rotating speed of the cylinder $(-4000 \leq \mathrm{w} \leq 4000)$. Except for the Hartmann number, which decelerates the flow rate, each of these parameters has a positive impact on the thermal transmission rate.
\end{abstract}

Keywords: hybrid nano-fluid; triangular cavity; magnetic field; convective flow

\section{Introduction}

Convection has always been the primary focus of research [1] for a variety of heating and cooling engineering systems. A modification of the geometrical shape of the system $[2,3]$ was recently agreed upon among researchers in order to achieve spectacular optimization of the heat-transfer performance, from circular [4] and square geometries [5] to non-square geometries [6-9] (triangular, trapezoidal, etc.) as it has been proven by many research papers that aspect ratio and type of the geometry have a huge impact on thermal performance [10-12]. Heat-transfer fluid has also been the subject of significant development. Conventional fluids such as water and ethylene glycol now contain dispersed nanoparticles [13] that ensure an enhancement in thermal conductivity [14]. Therefore, these "nano-fluids" with improved physical properties yield great results, improving heat transfer [15]. Other attempts have been made [16-20] resulting in hybrid nano-fluids with two suspended nanoparticles, supporting the notion of lower costs and greateradvantages; therefore, they are regarded as enhancing parameters for heat systems, considering their superior thermal characteristics due to the combination of nanoparticles, when compared to mono nano-fluids and classical fluids [21,22].

In this context, Kahveci [23] studied heat transfer in a differentially heated square enclosure filled with nano-fluids and reported improvement in Nusselt number when inserting nanoparticles. Torki and Etesami [24] experimentally investigated the impact of the volume fraction of nano-fluids on Nusselt number in a rectangular enclosure and reported a proportional relationship between these two features.

Mansour et al. [25] explored an inclined square cavity with nano-fluids and heating circular solid, while Alsaberi et al. [26] inserted a hot solid square in a cold square under the effect of a magnetic field and reported a non-linear influence on heat transfer. Selcuk et al. [27] reported that increasing magnetic induction decreases velocity, which, in turn, decelerates the flow. The work of Zhang et al. [28] supports these results, finding a 33\% 
reduction in cooling efficiency with increasing Hartmann number. Furthermore, Mahmoudi et al. [29] considered the Hartmann number parameter that restricted the heat-transfer rate. In this context, many studies were used to establish this research [30-36].

Ravnik et al. [37] studied natural convection in a cubic enclosure with a heated elliptical cylinder. Ishak et al. [38] numerically analyzed entropy generation in a classic trapezoid filled with alumina/water nano-fluid and an implemented immobile circular cylinder using the finite element method. Mebarek-Oudina et al. [39] studied the characteristics of a hybrid nano-fluid MHD flow in an annulus between a trapezoid and a rotating cylinder with a zigzagged wall.

Mahmoudi et al. [40] investigated nano-fluid flow in a triangular enclosure partially heated from below with a cold inclined wall. Majdi et al. [41] examined mixed convection in a lid-driven triangular enclosure with a motionless circle. Wang et al. [42] maintained a numerical approach for convection of a nano-fluid between a rotating circular cylinder and a conventional right-angled triangle, while Triveni and Panua [43] evaluated the impact of the aspect ratio of the hot wall in a triangular cavity and noticed a significant difference in the heat transfer rate as the caterpillar and zigzagged walls are more efficient than a linear wall. Other authors $[44,45]$ studied convective flow inside enclosures with different hot-shaped inner cylinders. Several other references were utilized to establish this work [46-51].

These studies reported interesting results regarding the impact of motion, speed of rotation, placement of the internal cylinder, and the properties of nano-fluids, and it has been demonstrated that triangular-shaped enclosures are incredibly effective in the process of altering the efficiency of the heat system [52,53].

Based on the preceding investigations, this paper numerically analyzes thermal transport in a previously unseen configuration: an original triangular porous chamber filled with magnetized $\mathrm{Cu}-\mathrm{TiO}_{2} / \mathrm{EG}$ hybrid nano-fluid and a spinning cylinder. The findings of this research will aid in achieving a better understanding of the effect of different cylinders inside the cavity, as well as expanding the contribution of sophisticated triangular geometries, which already have wide spread applications in industry [54-56] and are unquestionably adaptable in real-world applications, such as cooling electronic devices, solar heating systems, heat exchangers, solar collectors, etc. Aiming for high heat transmission efficiency under unusual settings, this work provides a significant contribution to future applications.

\section{Physical Model}

This study provides numerical insight into convection, owing to the magneto-hydrodynamic flow of a hybrid nano-fluid in a porous triangular enclosure described by the DarcyForchheimer-Brinkman model. The configuration presents a right-angled triangular cavity of $1 \mathrm{~m}$ length with a zigzagged inclined wall and an elliptical rotating cylinder along the $\mathrm{x}$-direction inserted in the center of the geometry in order to investigate mixed convection; this is combined with heat transfer due to the buoyancy forces that lead tonatural convection and to the rotational velocity of the cylinder that drives forced convection. Figure 1 depicts the porous setup that is exposed to a magnetic induction, $\mathrm{B}_{0}$, detailed in Table 1 , and filled with the $\mathrm{Cu}-\mathrm{TiO}_{2} / \mathrm{EG}$ hybrid nano-fluid featured in Table 2. The right-angled wall is cold with a fixed temperature, $\mathrm{T}_{\mathrm{c}}$, while the inclined wall is subject to a heating source and set as $T_{h}$. The base of the triangle and the cylinder are both adiabatic. 

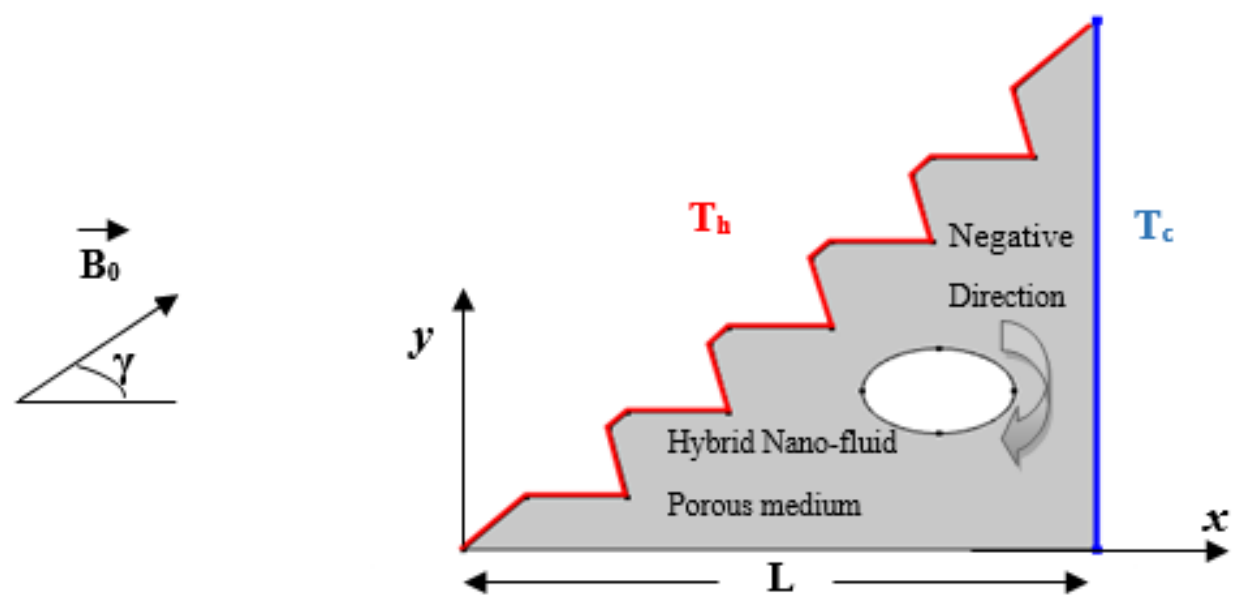

Figure 1. Configuration of the physical model.

Table 1. Magnetic flux-density range.

\begin{tabular}{cc|cc}
\hline Ha & \multicolumn{2}{c}{2550} & 100 \\
\hline B $_{\mathbf{0}}$ (Tesla) & 1351 & 2702 & 5404 \\
\hline
\end{tabular}

Table 2. Mesh-quality parameters.

\begin{tabular}{ccccc}
\hline Mesh & Extra Coarse & Coarse & Fine & Extra Fine \\
\hline Maximum element size (m) & 0.13 & 0.067 & 0.035 & 0.013 \\
\hline Minimum element size (m) & 0.005 & 0.003 & 0.001 & 0.00015 \\
\hline Curvature factor & 0.8 & 0.4 & 0.3 & 0.25 \\
\hline Growth rate & 1.3 & 1.2 & 1.13 & 1.08 \\
\hline Number of elements & 840 & 1984 & 3944 & 22184 \\
\hline Average quality & 0.7110 & 0.7736 & 0.7803 & 0.8003 \\
\hline
\end{tabular}

Boundary conditions of the domain:

$$
\begin{aligned}
& \text { The right-angled wall: } \mathrm{U}=0, \mathrm{~V}=0 \text { and } \mathrm{T}=\mathrm{T}_{\mathrm{c}} \\
& \text { The inclined wall: } \mathrm{U}=0, \mathrm{~V}=0 \text { and } \mathrm{T}=\mathrm{T}_{\mathrm{h}} \text {; } \\
& \text { The base wall : } \mathrm{U}=0, \mathrm{~V}=0 \text { and } \frac{\partial T}{\partial n}=0 \text {; } \\
& \text { The cylinder : } \mathrm{U}=\mathrm{w}, \mathrm{V}=0 \text { and } \frac{\partial T}{\partial n}=0 \text {. }
\end{aligned}
$$

\section{Grid Test}

The grid test is performed by studying several types of meshes in COMSOL multiphysics and assessing different parameters to enable the selection of the relevant mesh that provides valid results, considering our convective flow. Because algorithms in this software only provide high-quality elements with a value greater than 0.1 [57], our inquiry examined four types of elements indicated in Table 2 with satisfactory quality. The skewness measure quality is detailed; it allowed us to determine that increasing the element number improves the average quality of the mesh, indicating the dependability of the extra-fine mesh in numerical simulations. Furthermore, these four meshes performed an independence test at $\mathrm{Ra}=10^{5}$ and $\phi=0.04$ to calculate the Nusselt number. Table 3 shows the obtained results, which reveal that the deviations in Nusselt number decreased as the mesh quality increased, and we can conclude that the mesh with the highest quality, "extra fine" ensured accurate outcomes. Therefore, the extra-fine mesh presented in Figure 2 was selected for our study. 
Table 3. Grid-independence test.

\begin{tabular}{ccc}
\hline Mesh Quality & Nu & Nu Deviation \% \\
\hline 0.7110 & 3.9 & $12.05 \%$ \\
\hline 0.7736 & 4.37 & $7.09 \%$ \\
\hline 0.7803 & 4.68 & $0.64 \%$ \\
\hline 0.8003 & 4.71 & $/$ \\
\hline
\end{tabular}

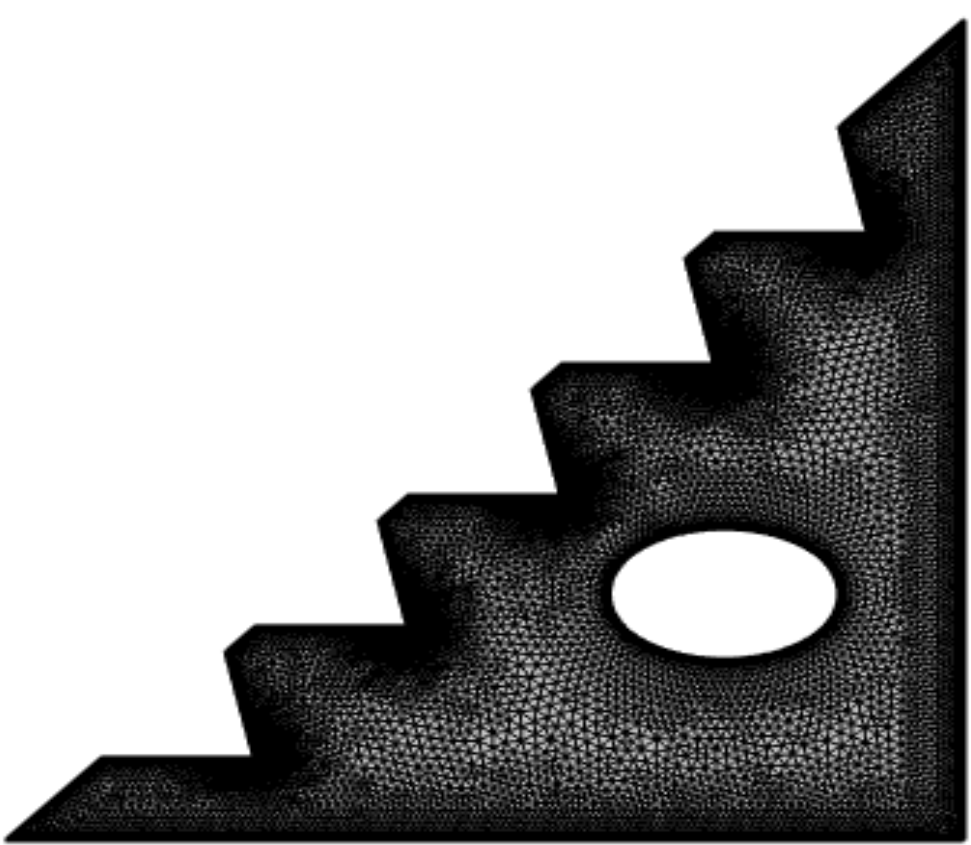

Figure 2. Mesh of the physical model.

\section{Formulation of the Problem}

\subsection{Equations}

The two-dimensional laminar convective flow in the studied triangular geometry is assumed to be stationary and incompressible. Thus, continuity and energy distribution in Cartesian coordinates are expressed as the following, according to [58,59]:

$$
\begin{aligned}
& \frac{\partial u}{\partial x}+\frac{\partial v}{\partial y}=0 \\
& \frac{\partial u}{\partial x}+\frac{\partial v}{\partial y}=0
\end{aligned}
$$

while the Navier-Stocks equations, which characterizethe flow of the hybrid nano-fluid, are described using the Darcy-Brinkman-Forchheimer model, which examines single-phase fluid circulation in a porous medium under the influence of magnetic fields [60], a model that has proven efficient and yields accurate outcomes [61]:

$$
\begin{gathered}
\frac{1}{\varepsilon^{2}}\left(u \frac{\partial u}{\partial x}+v \frac{\partial u}{\partial y}\right)=-\frac{1}{\rho_{h n f}} \frac{\partial p}{\partial x}-\vartheta_{h n f} \frac{u}{K}+ \\
\frac{\sigma_{h n f} B_{0}^{2}}{\rho_{h n f}}\left(v \sin (\gamma) \cos (\gamma)-u \sin ^{2}(\gamma)\right)-\frac{F_{C}}{\sqrt{K}} u|u|+\frac{\vartheta_{h n f}}{\varepsilon}\left(\frac{\partial^{2} u}{\partial x^{2}}+\frac{\partial^{2} u}{\partial y^{2}}\right) \\
\frac{1}{\varepsilon^{2}}\left(u \frac{\partial v}{\partial x}+v \frac{\partial v}{\partial y}\right)=-\frac{1}{\rho_{h n f}} \frac{\partial p}{\partial y}-\vartheta_{h n f} \frac{v}{K}+\beta_{h n f} g\left(T-T_{a v g}\right)+ \\
\frac{\sigma_{h n f} B_{0}^{2}}{\rho_{h n f}}\left(u \sin (\gamma) \cos (\gamma)-v \sin ^{2}(\gamma)\right)-\frac{F_{C}}{\sqrt{K}} v|u|+\frac{\vartheta_{h n f}}{\varepsilon}\left(\frac{\partial^{2} v}{\partial x^{2}}+\frac{\partial^{2} v}{\partial y^{2}}\right)
\end{gathered}
$$


where $K$ is permeability, $F_{c}$ is the Forchheimer coefficient, $|u|$ is the amplitude velocity, and $T_{\text {avg }}$ is the average temperature:

$$
K=\frac{\varepsilon^{3} d_{m}^{2}}{150(1-\varepsilon)^{2}}, F_{c}=\frac{b}{\sqrt{a} \varepsilon^{\frac{3}{2}}} \text { with }(a=150, b=1.75),|u|=\sqrt{u^{2}+v^{2}}, T_{a v g}=\frac{T_{h}+T_{c}}{2}
$$

The following dimensionless numbers and variables are used to adjust the MHD flow distribution:

- Dimensionless numbers

$$
R a=\frac{\beta_{b f} g\left(T_{h}-T_{C}\right) L^{3}}{\alpha_{b f} \vartheta_{b f}}, H a=L B_{0} \sqrt{\frac{\sigma_{b f}}{\mu_{b f}}}, D a=\frac{K}{L^{2}}, P r=\frac{\vartheta_{b f}}{\alpha_{b f}}
$$

- Dimensionless variables

$$
\theta=\frac{T-T_{f}}{T_{h}-T_{f}}, Y=\frac{y}{L}, X=\frac{x}{L}, V=\frac{v L}{\alpha_{b f}}, U=\frac{u L}{\alpha_{b f}}, P=\frac{\left(p+\rho_{b f} g_{y}\right) L^{2}}{\alpha_{b f}^{2} \rho_{b f}}
$$

The final governing dimensionless equations turn to:

$$
\begin{gathered}
\frac{\partial U}{\partial X}+\frac{\partial V}{\partial Y}=0 ; \\
\frac{1}{\varepsilon^{2}} \frac{\rho_{h n f}}{\rho_{b f}}\left(U \frac{\partial U}{\partial X}+V \frac{\partial U}{\partial Y}\right)=-\frac{\partial P}{\partial X}-\frac{\vartheta_{h n f}}{\vartheta_{b f}} \frac{P_{r}}{D_{a} \sqrt{R_{a}}} U+ \\
\frac{\sigma_{h n f}}{\rho_{h n f}} \frac{\rho_{b f}}{\rho_{h n f}} \frac{P_{r}}{\varepsilon} \frac{H_{a}^{2}}{\sqrt{R_{a}}}\left(V \sin (\gamma) \cos (\gamma)-U \sin ^{2}(\gamma)\right)-\frac{F_{C}}{\sqrt{D_{a}}} U|U| \\
+\frac{1}{\varepsilon} \frac{\vartheta_{h n f}}{\vartheta_{b f}} \frac{P_{r}}{\sqrt{R_{a}}}\left(\frac{\partial^{2} U}{\partial X^{2}}+\frac{\partial^{2} U}{\partial Y^{2}}\right) ; \\
\frac{1}{\varepsilon^{2}} \frac{\rho_{h n f}}{\rho_{b f}}\left(U \frac{\partial V}{\partial X}+V \frac{\partial V}{\partial Y}\right)=-\frac{\partial P}{\partial Y}-\frac{\vartheta_{h n f}}{\vartheta_{b f}} \frac{P_{r}}{\rho_{h n f} \sqrt{R_{a}}} \frac{\rho_{b f}}{\rho_{h n f}} \frac{P_{r}}{\varepsilon} \frac{H_{a}{ }^{2}}{\sqrt{R_{a}}}\left(U \sin (\gamma) \cos (\gamma)-V \sin ^{2}(\gamma)\right)-\frac{\beta_{\text {h }}}{\sqrt{D_{b f}}} V \mid U+ \\
+\frac{1}{\varepsilon} \frac{\vartheta_{h n f}}{\vartheta_{b f}} \frac{P_{r}}{\sqrt{R_{a}}}\left(\frac{\partial^{2} V}{\partial X^{2}}+\frac{\partial^{2} V}{\partial Y^{2}}\right) ; \\
U \frac{\partial \theta}{\partial X}+V \frac{\partial \theta}{\partial Y}=\frac{\alpha_{h n f}}{\alpha_{b f}}\left(\frac{\partial^{2} \theta}{\partial X^{2}}+\frac{\partial^{2} \theta}{\partial Y^{2}}\right)
\end{gathered}
$$

\subsection{Validation}

The finite-element method (FEM) was used and applied in the COMSOL multi-physics software 5.6 to solve the dimensionless governing equations presented above with the given boundary conditions. The accuracy of the present program was assessed, and the results are reported in Figure 3, which compares the current isotherms and streamlines to those of the numerical findings of [62], in which natural convection was explored in a basic triangular enclosure. 
a)
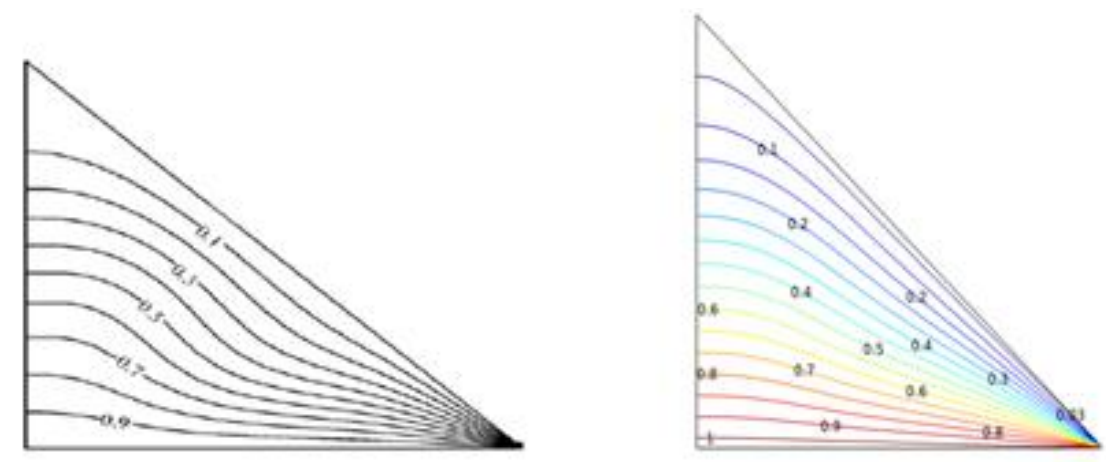

b)
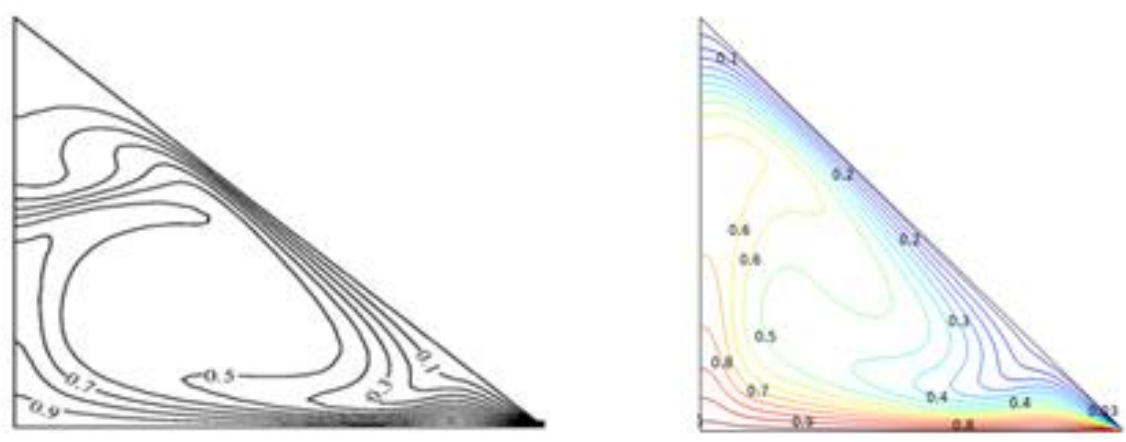

Figure 3. Isotherm and streamline comparison: previous work (left) and current work (right) for $\mathrm{Ha}=0(\mathbf{a}), \mathrm{Ra}=10^{4}(\mathbf{b})$, and $\mathrm{Ra}=10^{6}$.

\subsection{Properties of the Hybrid Nano-Fluid}

The volume fraction of the hybrid nano-fluid can be calculated as follows:

$$
\varphi=\varphi_{\mathrm{Cu}}+\varphi_{\mathrm{TiO}_{2}}
$$

The equations of the specific heat capacity, density, thermal conductivity, thermal expansion, and electrical conductivity of $\mathrm{Cu}$ and $\mathrm{TiO}_{2}$ nanoparticles, respectively, were obtained from $[63,64]$ and can be calculated as follows:

$$
\begin{gathered}
C p_{n p}=\frac{\varphi_{\mathrm{Cu}} \mathrm{C} p_{\mathrm{Cu}}+\varphi_{\mathrm{TiO}_{2}} \rho C p_{\mathrm{TiO}_{2}}}{\varphi} \\
\rho_{n p}=\frac{\varphi_{\mathrm{Cu}} \rho_{\mathrm{Cu}}+\varphi_{\mathrm{TiO}_{2}} \rho_{\mathrm{TiO}_{2}}}{\varphi} \\
k_{n p}=\frac{\varphi_{\mathrm{Cu}} k_{\mathrm{Cu}}+\varphi_{\mathrm{TiO}_{2}} k_{\mathrm{TiO}_{2}}}{\varphi} \\
\beta_{n p}=\frac{\varphi_{\mathrm{Cu}} \beta_{\mathrm{Cu}}+\varphi_{\mathrm{TiO}_{2}} \beta_{\mathrm{TiO}_{2}}}{\varphi} \\
\sigma_{n p}=\frac{\varphi_{\mathrm{Cu}} \sigma_{\mathrm{Cu}}+\varphi_{\mathrm{TiO}_{2}} \sigma_{\mathrm{TiO}_{2}}}{\varphi}
\end{gathered}
$$

while the equations of the hybrid nano-fluid are as follows [63,64]:

The density of the hybrid nano-fluid is defined as:

$$
\rho_{h n f}=(1-\varphi) \rho_{b f}+\varphi \rho_{h p}
$$

where $\rho_{b f}, \sigma_{b f}$ are the density and electrical conductivity of the base fluid, respectively; and $\rho_{n p}, \sigma_{n p}$ are the density and electrical conductivity of the used nanoparticles, respectively. Thus, the electrical conductivity of the hybrid nano-fluid is given by: 


$$
\sigma_{h n f}=(1-\varphi) \sigma_{b f}+\varphi \sigma_{n p}
$$

As a result, the thermal expansion and specific heat of the hybrid nano-fluid are calculated to as follows:

$$
\begin{gathered}
(\rho \beta)_{h n f}=(1-\varphi)(\rho \beta)_{b f}+\varphi(\rho \beta)_{n p} \\
(\rho C p)_{h n f}=(1-\varphi)(\rho C p)_{b f}+\varphi(\rho C p)_{n p}
\end{gathered}
$$

while the thermal and electrical conductivity of the hybrid nano-fluid are obtained from the following equations:

$$
\begin{gathered}
\frac{k_{h n f}}{k_{b f}}=\frac{k_{n p}+(n-1) k_{b f}-(n-1)\left(k_{b f}-k_{n p}\right) \varphi}{k_{n p}+(n-1) k_{b f}-\left(k_{b f}-k_{n p}\right) \varphi} \\
\frac{\sigma_{h n f}}{\sigma_{b f}}=1+\frac{3\left(\sigma_{n p}-\sigma_{b f}\right) \varphi}{\left(\sigma_{n p}+2 \sigma_{b f}\right)-\left(\sigma_{n p}-\sigma_{b f}\right) \varphi}
\end{gathered}
$$

Thermal diffusivity of the hybrid nano-fluid is considered as:

$$
\alpha_{h n f}=\frac{k_{h n f}}{(\rho C p)_{h n f}}
$$

The dynamic viscosity is given as follows, according to the Brinkman model [58]:

$$
\mu_{h n f}=\frac{\mu_{b f}}{(1-\varphi)^{2.5}}
$$

The thermo-physical characteristics of the hybrid nano-fluid used in this study are presented in Table 4 [65].

Table 4. Thermo-physical properties of $\mathrm{Cu}-\mathrm{TiO}_{2} / \mathrm{EG}$ hybrid nano-fluid.

\begin{tabular}{cccc}
\hline & $\mathbf{C u}$ & $\mathbf{T i O}_{\mathbf{2}}$ & EG \\
\hline $\mathrm{C}_{\mathrm{P}}\left(\mathrm{J} \cdot \mathrm{K}^{-1} \cdot \mathrm{Kg}^{-1}\right)$ & 385 & 686.2 & 2415 \\
$\rho\left(\mathrm{Kg} \cdot \mathrm{m}^{-3}\right)$ & 8933 & 4250 & 1114 \\
$\mathrm{k}\left(\mathrm{W} . \mathrm{K}^{-1} \cdot \mathrm{m}^{-1}\right)$ & 401 & 8.95 & 0.252 \\
$\beta\left(\mathrm{K}^{-1}\right)$ & $1.67 \times 10^{-5}$ & $0.9 \times 10^{-5}$ & $57 \times 10^{-5}$ \\
$\sigma(\mathrm{Ohm} \cdot \mathrm{m})^{-1}$ & $5.96 \times 10^{-7}$ & $2.38 \times 10^{-6}$ & $5.5 \times 10^{-6}$ \\
\hline
\end{tabular}

\section{Results and Discussion}

This section will provide the numerical results obtained by streamline and isotherm contours, as well as the average Nusselt number for three major parameters: Rayleigh number $\left(10^{3} \leq \mathrm{Ra} \leq 10^{6}\right)$, to study the convective heat transfer in the laminar regime and explore its features near the transition mode; Hartmann number $(0 \leq \mathrm{Ha} \leq 100)$, in order to investigate the relation between magnetic-field strength heat-transfer efficiency; and the volume fraction of the hybrid nano-fluid $(0.02 \leq \phi \leq 0.08)$, to evaluate the presence of nanoparticle in a porous medium with constant properties: Darcy number, $\mathrm{Da}=0.1$; porosity, $\varepsilon=0.4$. Additionally the following geometrical factors are discussed: the impact of the rotation of the internal cylinder with a speed, $w$, of $(-4000 \leq w \leq 4000)$, as well as the placement of the cylinder and several shaped obstacles (square, circle, elliptic, and triangle).

\subsection{Impact of the Nano-Fluid Volume Fraction}

At $\mathrm{Ra}=10^{5}$ (Figure 4 ), the average $\mathrm{Nu}$ number appears to grow with the volume fraction where natural convection significantly dominates. Augmenting the concentration 
of the hybrid nano-fluid corresponds to an increase in the presence of nanoparticles, both $\mathrm{Cu}$ and $\mathrm{TiO}_{2}$, that present enhanced thermo-physical characteristics compared to classical fluids, as presented in Table 4, particularly their thermal conductivity. It worth mentioning that these properties improve the thermal conductivity of the hybrid nano-fluid and also increment the surface area of the nanoparticles [58]. Therefore, $\mathrm{Nu}_{\text {avg }}$ is proportional to the presence and the volume fraction of the hybrid nano-fluid, and such correlation contributes to convective transfer.

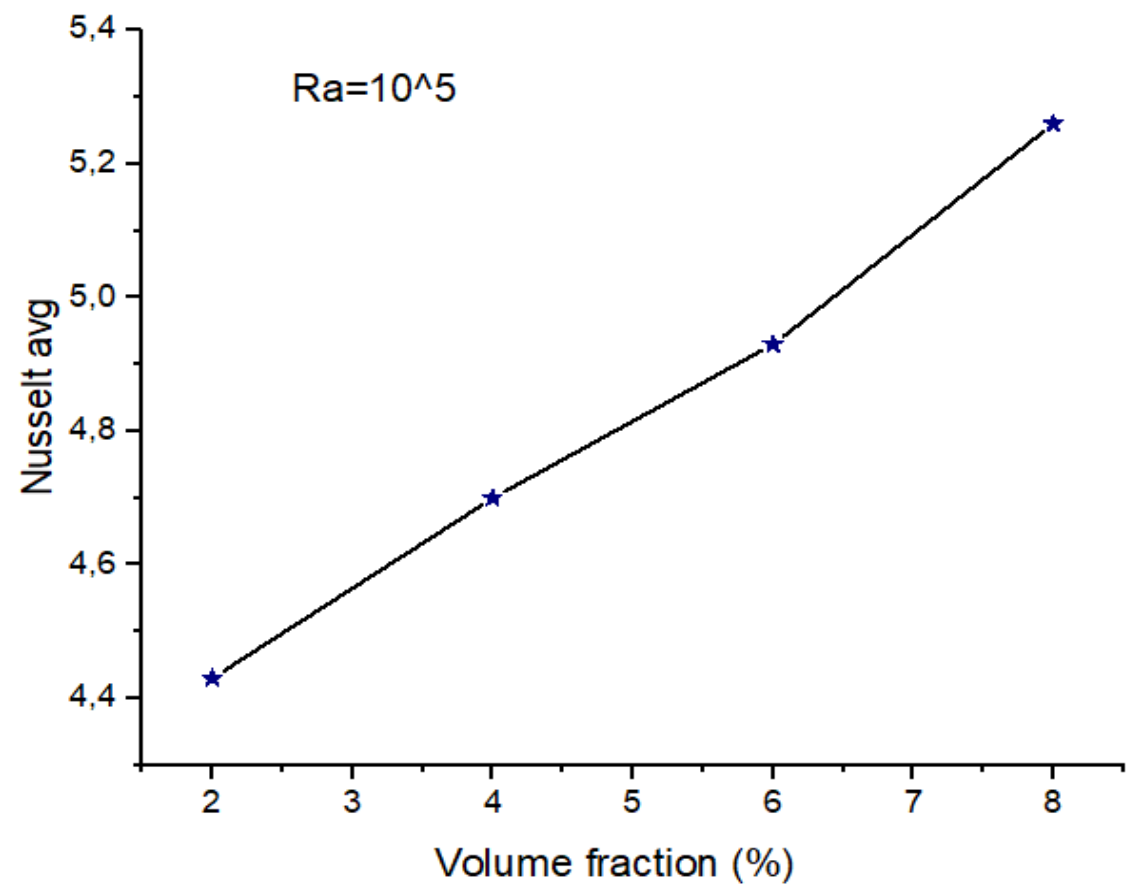

Figure 4. Average $\mathrm{Nu}$ for $\mathrm{Ra}=10^{5}, \mathrm{Ha}=0$, and $\mathrm{w}=0$.

Figure 5 presents the impact of the hybrid nano-fluid concentration on heat-transfer features, isotherms, and streamlines. It is shown that incrementing the volume fraction of the nanoparticles has only a minor effect on streamline and isotherm contours, with a slight modification to the detected stream-function value. The enhanced heat transfer properties provided by the increase in the volume fraction also intensify entropy generation [66,67], which results in decremented stream-function values and a reduced heat-transmission rate.

Although the presence of nano-fluids is intended to boost convection, increasing their concentration also increases entropy production. Therefore, an equilibrium must be considered when augmenting $\phi$.

\subsection{Impact of Rayleigh Number}

Figure 6 illustrates the influence of Ra number on streamlines for $2 \%$ of the hybrid Nano-fluid and no presence of the magnetic field. The results reveal that increasing $\mathrm{Ra}$ causes linear growth in the stream functions.

It is shown in Figure 6 that an increasing Ra number causes the vortices in the surroundings of the cylinder to grow larger and stronger, enabling the free convection to be significantly exploited, which strengthens the velocity field and speeds up the flow. As a result, the hybrid nano-fluid is heated up and becomes less dense, allowing buoyancy forces to ascend the hybrid nano-fluid and focus the flow on the upper part of the cylinder. Therefore, heat transfer is a trend of Rayleigh number since its enhancement indicates better heat transmission.

This enhancement is noted to be in a high range for $\mathrm{Ra}=10^{6}$, with a stream-function value a hundred times greater than $\Psi_{\max }$ at $\mathrm{Ra}=10^{4}$ and ten times greater than $\Psi_{\max }$ at 
$\mathrm{Ra}=10^{5}$. These results show that approaching the critical Rayleigh value (almost $10^{9}$ ) engenders significant values of heat transfer.

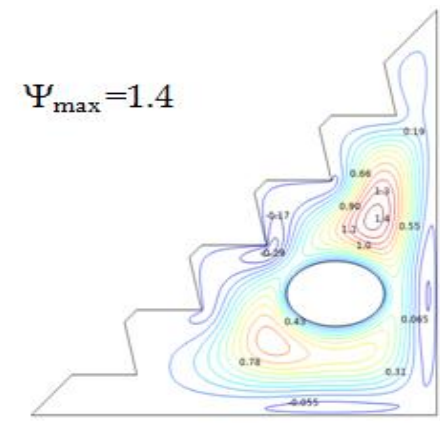

a) $\varphi=0.04$
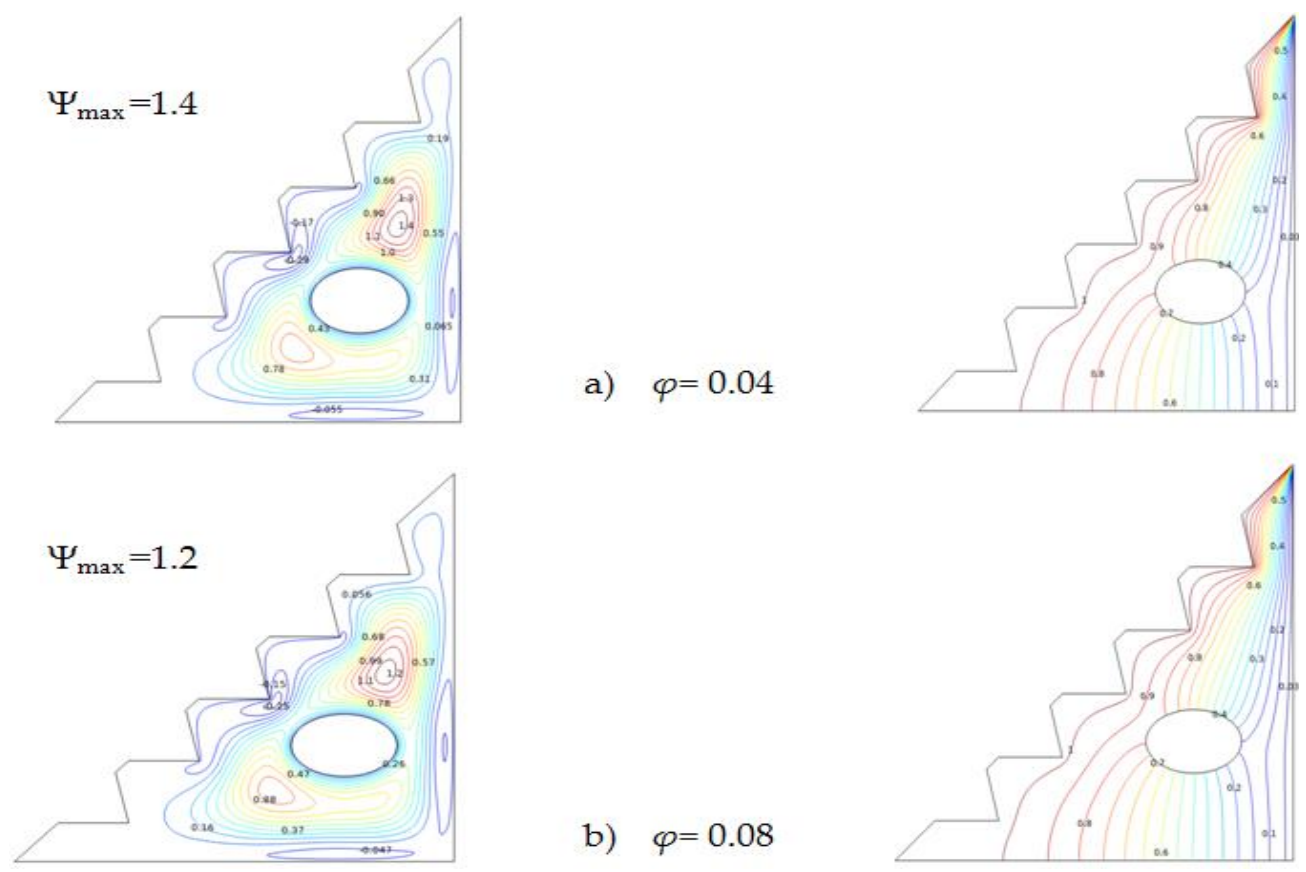

b) $\varphi=0.08$

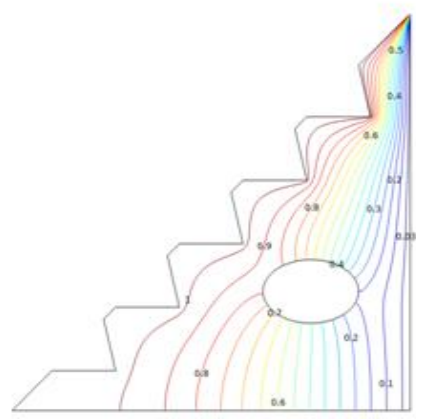

Figure 5. Streamlines and isotherms for $\mathrm{Ra}=10^{5}, \mathrm{Ha}=0$, and $\mathrm{w}=0$.

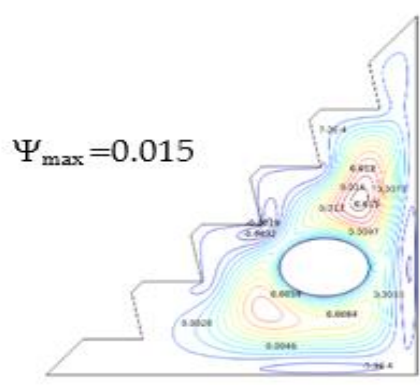

$\operatorname{Ra}=10^{3}$

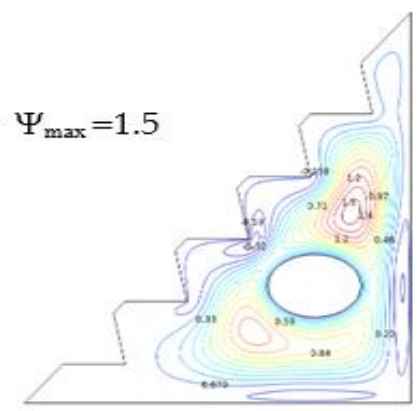

$\mathrm{Ra}=10^{5}$

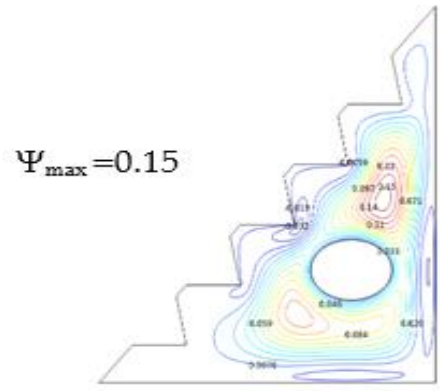

$\mathrm{Ra}=10^{4}$

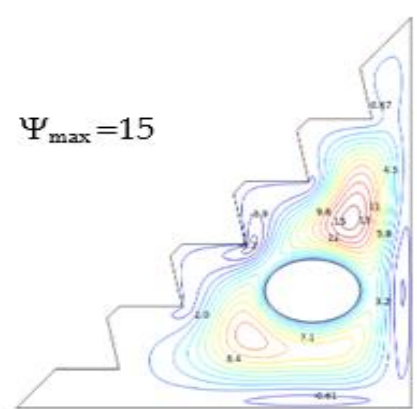

$\mathrm{Ra}=10^{6}$

Figure 6. Streamlines for $\mathrm{Ha}=0, \mathrm{w}=0$, and $\phi=0.02$.

\subsection{Impact of Hartmann Number}

On the other hand, as shown in Figure 7, the presence of a magnetic field diminishes the convective transfer rate, as Lorentz forces inhibit the development of vortices and thus reduce the velocity of the nano-fluid and suppress the flow distribution. In the case where 
no magnetic induction was introduced, two large vortices were formed around the cylinder, which smoothed the flow of the hybrid nano-fluid. With an increasing Hartmann number, stream-function values were reduced as vortices shrunk in size and nearly disappeared in the upper part of the enclosure, causing the flow to aggregate towards the bottom wall. In conclusion, Hartmann number might be regarded as a limiting parameter for heat flow.

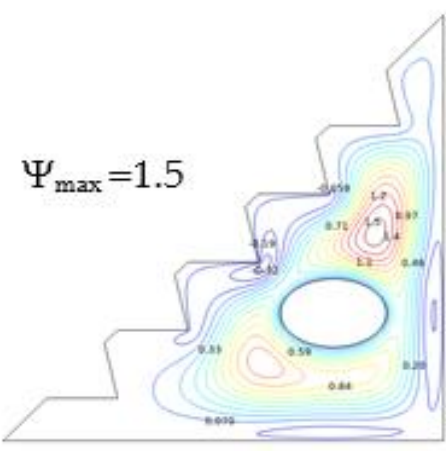

$\mathrm{Ha}=0$

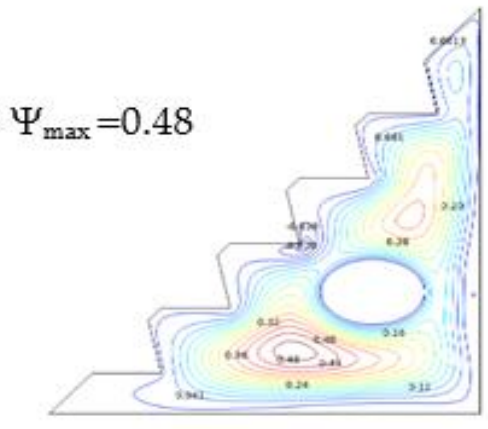

$\mathrm{Ha}=50$

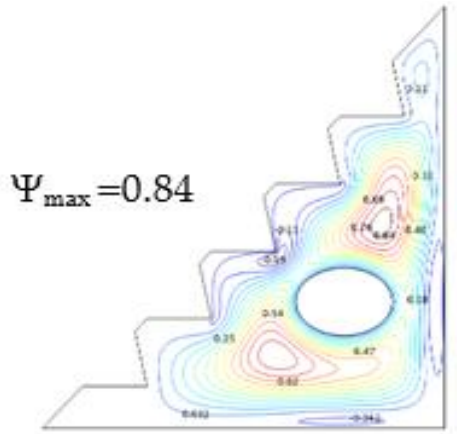

$\mathrm{Ha}=25$

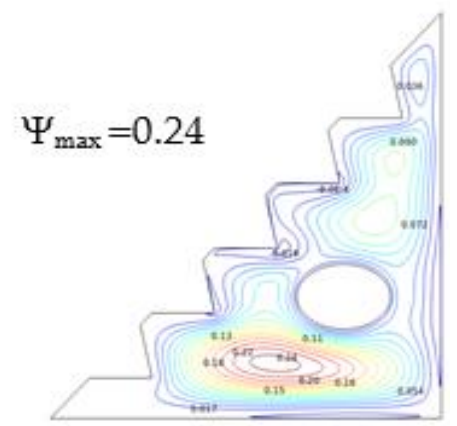

$\mathrm{Ha}=100$

Figure 7. Streamlines for $\mathrm{Ra}=10^{5}, \mathrm{w}=0$, and $\phi=0.02$.

\subsection{Impact of the Geometrical Features}

\subsubsection{Effect of Cylinder Placement}

Figure 8 highlights the distinctions between the two elliptical obstacle placements for $2 \%$ of the hybrid nano-fluid and no subjection to a magnetic field. It is observed that for $\mathrm{Ra}=10^{4}$, the temperature distribution is directly affected by the location of the cylinder; the temperature variation in the configuration in the case of (b) provides better heat transfer, as it enables the flow to be distributed in the surrounding central section of the enclosure, with a large vortex that provides great stream-function values, which permits buoyancy forces to freely drive the hybrid nano-fluid flow, thereby significantly exploiting natural convection. In contrast to case (a), where the elliptical cylinder is positioned in the center of the enclosure, in this scenario, the flow is divided into two vortices: a large upper big vortex that offers a lower stream-function value than case (b) and a smaller one obstructed in the bottom of the enclosure, therefore obtaining less thermal transmission. According to these findings, it has been demonstrated that placing the obstacle at the bottom of the enclosure improves the heat-transfer rate.

\subsubsection{Effect of the Rotation of the Cylinder}

Mixed convection was investigated at $\mathrm{Ra}=10^{5}$, and for $4 \%$ of the hybrid nano-fluid, the findings are shown in Figure 9, which displays several streamlines, exhibiting the impact of the ellipse's rotational velocity. A negative rotation value indicates a clockwise motion. 

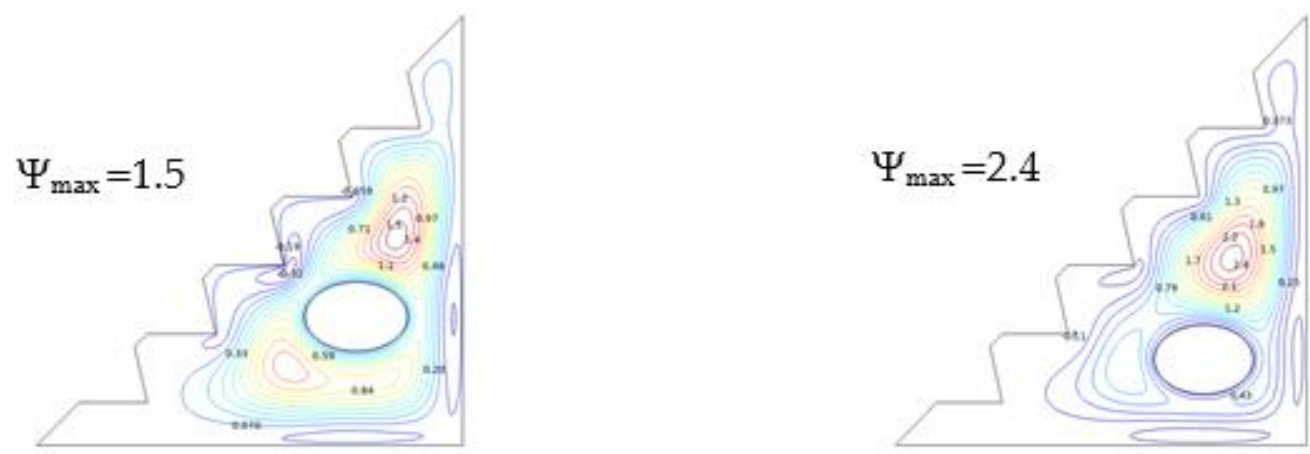

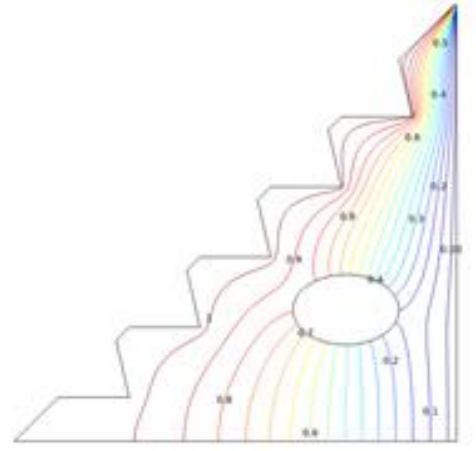

Case (a), Ra $=10^{4}$

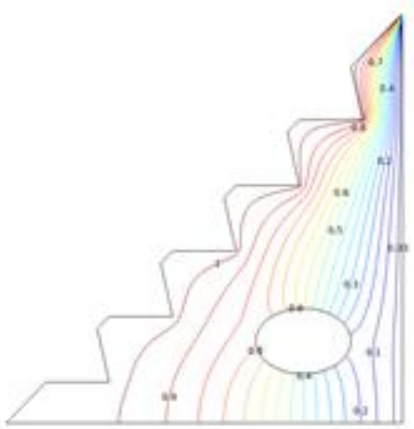

Case (b), Ra $=10^{5}$

Figure 8. Streamlines and isotherms for $\mathrm{Ha}=0, \mathrm{w}=0$, and $\phi=0.02$.
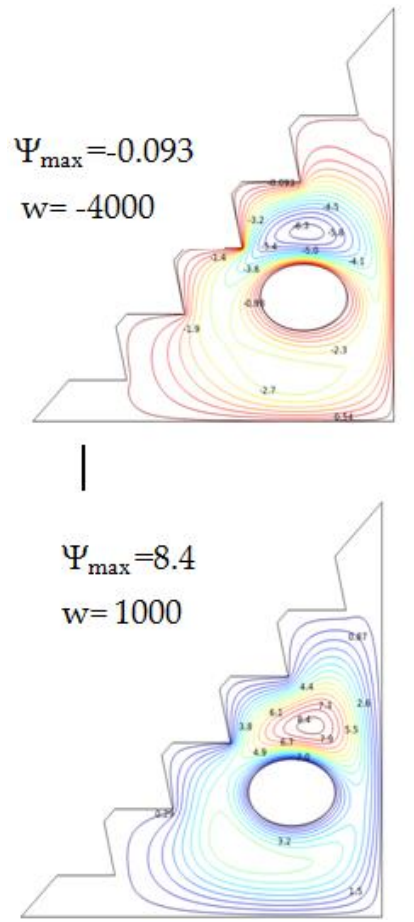
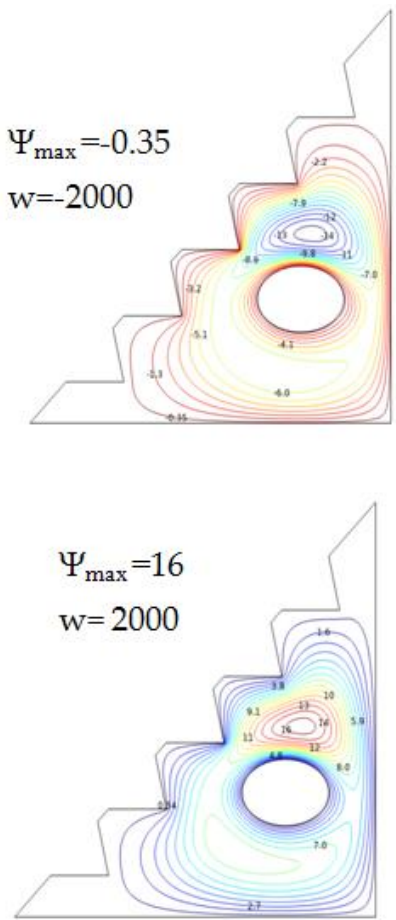
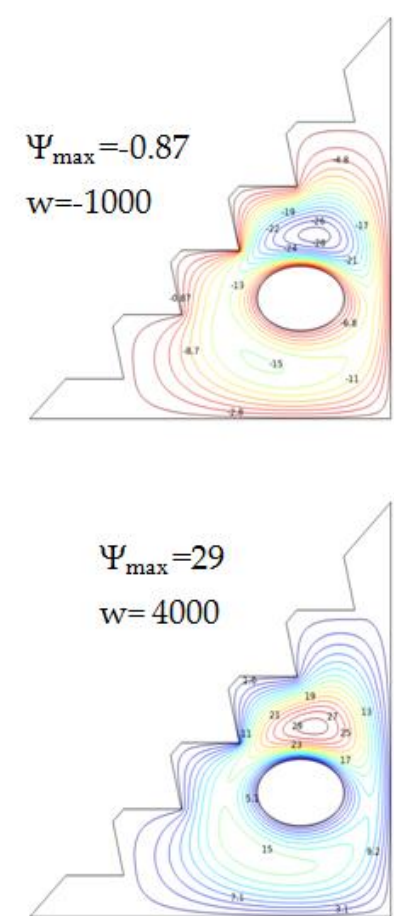

Figure 9. Streamlines via $\mathrm{w}$ and $\mathrm{Ra}=10^{5}, \phi=0.04$, and $\mathrm{Ha}=0$.

Leading the cylinder counter-clock wise reveals the benefits of the convective transfer; convection, due to the positive rotation, is concentrated around the cylinder, where this movement produces a increase in stream functions as an outcome of high values of velocity. As a result, large vortices are created; hence, the flow of the hybrid nano-fluid is accelerated. Natural convection is oriented towards the walls of the enclosure, where buoyancy forces 
are amplified. Therefore, augmenting the cylinder's angular velocity in a counter-clockwise direction intensifies mixed convection and results in a higher heat-transfer rate. Clockwise movement, on the other hand, diminishes the heat-transfer rate, and fewer stream-function values are reported.

According to these findings, the direction of movement and the value of the angular rotational velocity of the cylinder may be employed as essential parameters for improving heat transmission.

\subsubsection{Effect of the Different Obstacles}

The streamlines and isotherms produced and illustrated in Figure 10 investigate the influence of several obstacles in the considered geometry on the flow distribution. The findings demonstrate that the square and circular obstruction appear to slow the flow by producing small vortices compared to the triangular obstacle, which provides increased heat-transfer since it delivers the greatest values of stream function. The two vortices arestretched around this cylinder, which provides more space for flow distribution, thereby strengthening heat transfer. Temperature variations also significantly contribute to improved buoyant forces, which drive and boost natural convection.
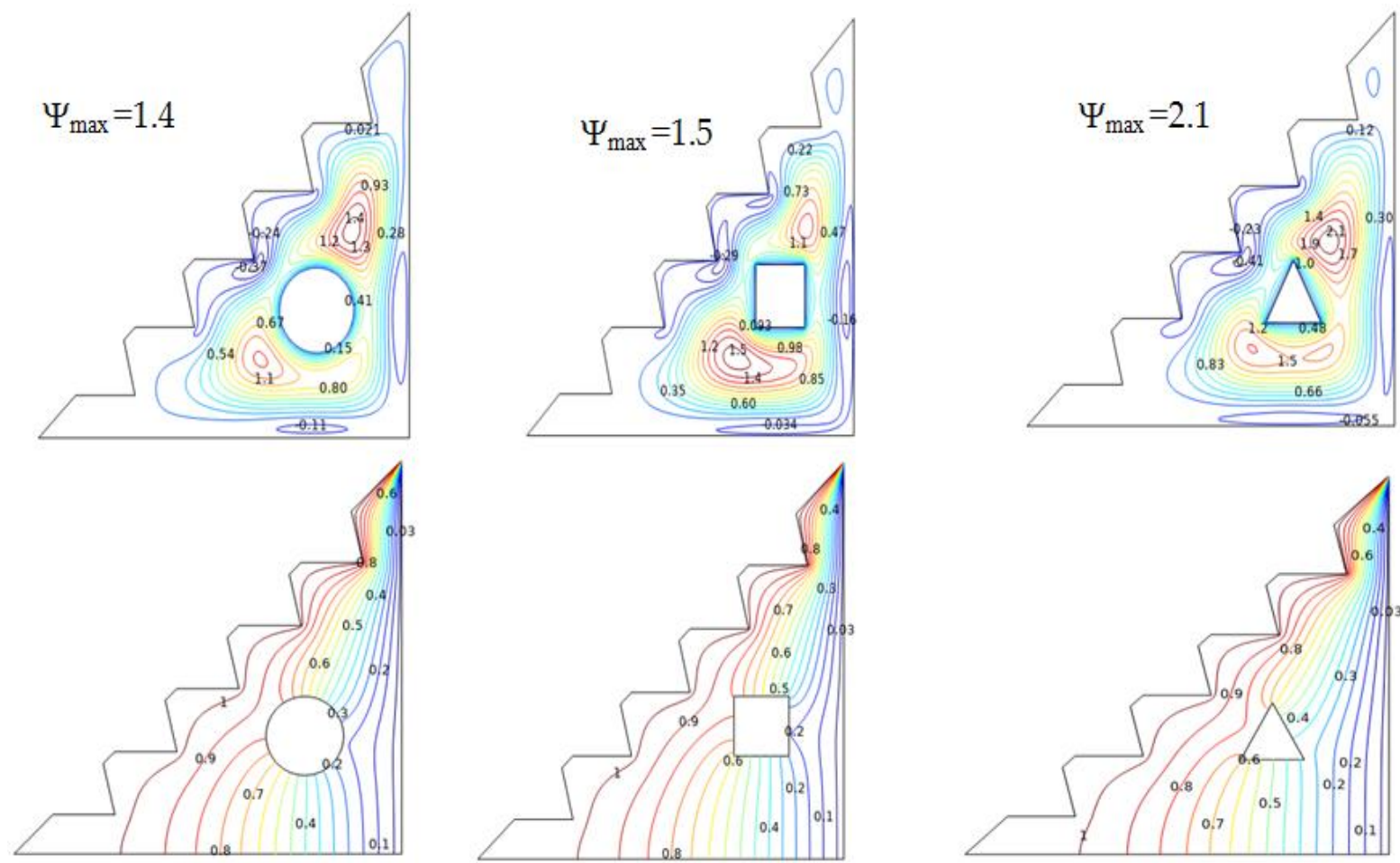

Figure 10. Streamlines and isotherms for $\mathrm{w}=0, \mathrm{Ha}=0, \mathrm{Ra}=10^{5}$, and $\phi=0.02$.

Furthermore, Figure 11 demonstrates that the triangular barrier provides improved heat-transfer efficiency by presenting the highest peak of $\mathrm{Nu}_{\mathrm{avg}}$ values when compared to the other cylinders. The geometrical features of the triangle and the uniform space provided around it make it easier for the hybrid nano-fluid to disperse, which can help amplify and alter the average $\mathrm{Nu}$ number and therefore convective transfer [68].

Additionally, the square, elliptic, and circular cylinders appear to have similar average Nusselt values; these cylinders should be further investigated by altering their radius. 


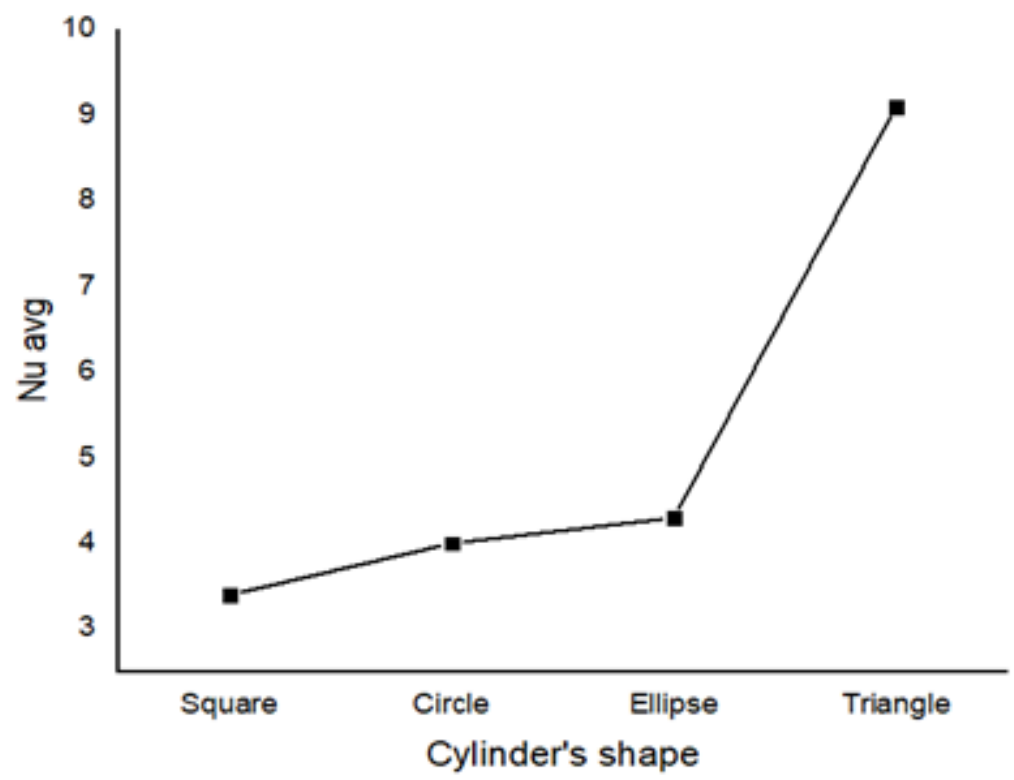

Figure 11. Average Nusselt values for $\mathrm{w}=0, \mathrm{Ha}=0, \mathrm{Ra}=10^{5}$, and $\phi=0.02$.

\section{Conclusions}

In this paper, we performed a numerical study in order to investigate geometrical parameters and discussed which configuration is advantageous in terms of enhancement of convective heat transmission. The findings concerning streamlines, isotherms, and average Nusselt number obtained by altering $\mathrm{Ra}, \phi$, and $\mathrm{Ha}$ in the first examination documenting heat transfer in such a setup, using $\mathrm{Cu}-\mathrm{TiO}_{2} / \mathrm{EG}$ hybrid nano-fluid under magnetic-field influence reveal that incrementing the concentration of the working fluid from 0.02 to 0.08 improves the Nusselt number by 19\%. Enhancing the Rayleigh number also accelerates the flow and strengthens the velocity field.

This enhancement is further boosted by the inclusion of counter-clockwise rotating cylinders in the enclosure, as well as triangular obstacles, which augment the Nu number by almost $120 \%$ compared to square, circular, and elliptical obstacles. However, this improvement is decremented when theenclosure is subjected to a magnetic field, as increasing Hartmann number reduced stream-function values and weakened the convective flow. Based on these findings, the following conclusions can be drawn:

- $\quad$ Rayleigh number and the volume fraction of the nanoparticles can be considered crucial features in modulating convection.

- The existence of a magnetic field, and therefore increasing Hartmann number, restricts heat transfer.

- Thermal transmission can be improved by using triangular obstacles.

- The angular velocity of the cylinder can alter the efficiency of the convective flow.

- The location of the obstacle is a key parameter to adjust the thermal transfer.

Author Contributions: All authors have the same contribution in this manuscript. All authors have read and agreed to the published version of the manuscript.

Funding: This research received no external funding.

Data Availability Statement: Data will be made available on request.

Acknowledgments: The authors would like to thank the Deanship of Scientific Research at Umm Al-Qura University for supporting this work; grant code: (22UQU4240002DSR02).

Conflicts of Interest: The authors declare no conflict of interest. 


\section{Abbreviations}

$\mathrm{u}, \mathrm{v} \quad$ Velocity components $\left(\mathrm{m} \cdot \mathrm{s}^{-1}\right)$

$\mathrm{U}, \mathrm{V}$ Dimensionless velocity components

$\mathrm{x}, \mathrm{y} \quad$ Cartesian coordinates (m)

$\mathrm{X}, \mathrm{Y}$ Dimensionless Cartesian coordinates

Pressure $\left(\mathrm{N} \cdot \mathrm{m}^{-2}\right)$

P Dimensionless pressure

$\rho \quad$ Density $\left(\mathrm{Kg} \cdot \mathrm{m}^{-3}\right)$

g Gravitational acceleration $\left(\mathrm{m} \cdot \mathrm{s}^{-2}\right)$

$\mathrm{T} \quad$ Temperature (K)

$\mathrm{T}_{\text {avg }} \quad$ Average temperature (K)

$\theta \quad$ Dimensionless temperature

$\alpha \quad$ Thermal diffusivity $\left(\mathrm{m}^{2} \cdot \mathrm{s}^{-1}\right)$

$v \quad$ Kinematic viscosity $\left(\mathrm{m}^{2} \cdot \mathrm{s}^{-1}\right)$

K Permeability $\left(\mathrm{H} \cdot \mathrm{m}^{-1}\right)$

$\varepsilon \quad$ Porosity

$\sigma \quad$ Electric conductivity $(\mathrm{Ohm} \mathrm{m})^{-1}$

$\mathrm{B}_{0} \quad$ Magnetic field density (Tesla)

$\mathrm{k}$ Thermal conductivity ratio $\left(\mathrm{W} \mathrm{K}^{-1} \mathrm{~m}^{-1}\right)$

$\mathrm{Cp} \quad$ Specific heat $\left(\mathrm{J} \mathrm{K}^{-1} \mathrm{Kg}^{-1}\right)$

$\beta \quad$ Thermal expansion $\left(\mathrm{K}^{-1}\right)$

$\mu \quad$ Dynamic viscosity $\left(\mathrm{Kg} \cdot \mathrm{m}^{-1} \cdot \mathrm{s}^{-1}\right)$

$\phi \quad$ Volume fraction of the nanoparticles

$\gamma \quad$ Inclination angle of the magnetic field

w Velocity of rotation( $\mathrm{rad} / \mathrm{s}$ )

$\Psi \quad$ Stream function

L Length of the enclosure (m)

Subscripts

h Hot

c Cold

EG Ethylene glycol

$\mathrm{Cu} \quad$ Copper

$\mathrm{TiO}_{2}$ Titanium dioxide

MHD Magneto-hydrodynamic

Nf Nano-fluids

hnf Hybrid nano-fluid

Bf Base fluid

np Nanoparticle

Max Maximum

Fc Forcheimer coefficient

$\mathrm{Ra}$ Rayleigh

$\mathrm{Nu} \quad$ Nusselt

Ha Hartmann

Da Darcy

Pr Prandt

\section{References}

1. Unger, S.; Beyer, M.; Pietruske, H.; Szalinski, L.; Hampel, U. Natural convection heat transfer performance of additively manufactured tube bundle heat exchangers with novel fin design. Heat Mass Transf. 2021, 57, 1193-1203. [CrossRef]

2. Rahimi, A.; Dehghan Saee, A.; Kasaeipoor, A.; Hasani Malekshah, E. A comprehensive review on natural convection flow and heat transfer. Int. J. Numer. Methods Heat Fluid Flow 2019, 29, 834-877. [CrossRef]

3. Baïri, A.; Zarco-Pernia, E.; De María, J.M. A Review on Natural Convection in Enclosures for Engineering Applications. The Particular Case of the Parallelogrammic Diode Cavity. Appl. Therm. Eng. 2014, 63, 304-322. [CrossRef]

4. Akbari, A.; Mohammadian, E.; Alavi Fazel, S.A.; Shanbedi, M.; Bahreini, M.; Heidari, M.; Babakhani Dehkordi, P.; Che Mohamed Hussein, S.N. Natural Convection from the Outside Surface of an Inclined Cylinder in Pure Liquids at Low Flux. ACS Omega 2019, 4, 7038-7046. [CrossRef] [PubMed] 
5. Saeid, N.H. Natural Convection in a Square Cavity with Discrete Heating at the Bottom with Different Fin Shapes. Heat Transf. Eng. 2018, 39, 154-161. [CrossRef]

6. Kent, E.F. Numerical analysis of laminar natural convection in isosceles triangular enclosures for cold base and hot inclined walls. Mech. Res. Commun. 2009, 36, 497-508. [CrossRef]

7. Das, D.; Roy, M.; Basak, T. Studies on natural convection within enclosures of various (non-square) shapes-A review. Int. J. Heat Mass Transf. 2017, 106, 356-406. [CrossRef]

8. Teamah, M.A.; Shehata, A.I. Magnetohydrodynamic double diffusive natural convection in trapezoidal cavities. Alex. Eng. J 2016, 55, 1037-1046. [CrossRef]

9. Mebarek-Oudina, F.; Keerthi Reddy, N.; Sankar, M. Heat Source location Effects on Buoyant Convection of Nanofluids in an Annulus. In Advances in Fluid Dynamics, Lecture Notes in Mechanical Engineering; Springer: Cham, Switzerland, 2021 ; pp. 923-937. [CrossRef]

10. Chang, B.H.; Mills, A.F. Effect of aspect ratio on forced convection heat transfer from cylinders. Int. J. Heat Mass Transf. 2004, 47, 1289-1296. [CrossRef]

11. Muthtamilselvan, M.; Sureshkumar, S. Impact of aspect ratio on a nanofluid-saturated porous enclosure. Mech. Ind. 2017, $18,501$. [CrossRef]

12. Mohammadifar, H.; Sajjadi, H.; Rahnama, M.; Jafari, S.; Wang, Y. Investigation of Nanofluid Natural Convection Heat Transfer in Open Ended L-shaped Cavities utilizing LBM. J. Appl. Comput. Mech. 2021, 7, 2064-2083. [CrossRef]

13. Holkar, C.R.; Jain, S.S.; Jadhav, A.J.; Pinjari, D.V. Chapter 14-Scale-Up Technologies for Advanced Nanomaterials for Green Energy: Feasibilities and Challenges. In Nanomaterials for Green Energy; Bhanvase, B.A., Pawade, V.B., Dhoble, S.J., Sonawane, S.H., Ashokkumar, M., Eds.; Elsevier: Amsterdam, The Netherlands, 2018; pp. 433-455.

14. Hwang, Y.J.; Ahn, Y.C.; Shin, H.S.; Lee, C.G.; Kim, G.T.; Park, H.S.; Lee, J.K. Investigation on characteristics of thermal conductivity enhancement of nanofluids. Curr. Appl. Phys. 2006, 6, 1068-1071. [CrossRef]

15. Ali, N.; Teixeira, J.A.; Addali, A. A Review on Nanofluids: Fabrication, Stability, and Thermophysical Properties. J. Nanomater. 2018, 2018, 6978130. [CrossRef]

16. Sajid, M.U.; Ali, H.M. Thermal conductivity of hybrid nanofluids: A critical review. Int. J. Heat Mass Transf. 2018, 126, 211-234. [CrossRef]

17. Dhif, K.; Mebarek-Oudina, F.; Chouf, S.; Vaidya, H.; Chamkha, A.J. Thermal Analysis of the Solar Collector Cum Storage System using a Hybrid-Nanofluids. J. Nanofluids 2021, 10, 634-644. [CrossRef]

18. Das, P.K. A review based on the effect and mechanism of thermal conductivity of normal nanofluids and hybrid nanofluids. J. Mol. Liq. 2017, 240, 420-446. [CrossRef]

19. Dadheech, P.K.; Agrawal, P.; Mebarek-Oudina, F.H.; Abu-Hamdeh, N.; Sharma, A. Comparative heat transfer analysis of $\mathrm{MoS}_{2} / \mathrm{C}_{2} \mathrm{H}_{6} \mathrm{O}_{2}$ and $\mathrm{MoS}_{2}-\mathrm{SiO}_{2} / \mathrm{C}_{2} \mathrm{H}_{6} \mathrm{O}_{2}$ nanofluids with natural convection and inclined magnetic field. J. Nanofluids 2020, 9, 161-167. [CrossRef]

20. Khan, U.; Zaib, A.; Mebarek-Oudina, F. Mixed Convective Magneto Flow of $\mathrm{SiO}_{2}-\mathrm{MoS}_{2} / \mathrm{C}_{2} \mathrm{H}_{6} \mathrm{O}_{2}$ Hybrid Nanoliquids Through a Vertical Stretching/Shrinking Wedge: Stability Analysis. Arab. J. Sci. Eng. 2020, 45, 9061-9073. [CrossRef]

21. Sarkar, J.; Ghosh, P.; Adil, A. A review on hybrid nanofluids: Recent research, development and applications. Renew. Sustain. Energy Rev. 2015, 43, 164-177. [CrossRef]

22. Eshgarf, H.; Kalbasi, R.; Maleki, A.; Shadloo, M.S.; Karimipour, A. A review on the properties, preparation, models and stability of hybrid nanofluids to optimize energy consumption. J. Therm. Anal. Calorim. 2021, 144, 1959-1983. [CrossRef]

23. Kahveci, K. Buoyancy Driven Heat Transfer of Nanofluids in a Tilted Enclosure. J. Heat Transf. 2010, 132, 062501. [CrossRef]

24. Torki, M.; Etesami, N. Experimental investigation of natural convection heat transfer of $\mathrm{SiO}_{2} /$ water nanofluid inside inclined enclosure. J. Therm. Anal. Calorim. 2019, 139, 1565-1574. [CrossRef]

25. Mansour, M.A.; Rama Subba Reddy, G.; Sadia, S.; Rashad, A.M.; Salah, T. Unsteady MHD natural convection flow of a nanofluid inside an inclined square cavity containing a heated circular obstacle. Int. J. Nonlinear Sci. Numer. Simul. 2021, 000010151520200138. [CrossRef]

26. Alsabery, A.; Sheremet, M.; Chamkha, A.; Hashim, I. MHD convective heat transfer in a discretely heated square cavity with conductive inner block using two-phase nanofluid model. Sci. Rep. 2018, 8, 7410. [CrossRef]

27. Selcuk, S.; Ziyaddin, R.; Erol, A. Combined effects of magnetic and electrical field on the hydrodynamic and thermophysical parameters of magnetoviscous fluid flow. Int. J. Heat Mass Transf. 2015, 86, 426-432.

28. Zhang, J.; Anjal, H.A.; Msmali, A.; Wange, F.; Nofal, T.A.; Selim, M.M. Heat transfer of nanomaterial with involve of MHD through an enclosure. Case Stud. Therm. Eng. 2022, 30, 101747. [CrossRef]

29. Mahmoudi, A.; Mejri, I.; Abbassi, M.A.; Omri, A. Lattice Boltzmann simulation of MHD natural convection in a nanofluid-filled cavity with linear temperature distribution. Powder Technol. 2014, 256, 257-271. [CrossRef]

30. Shahsavar, A.; Noori, S.; Toghraie, D.; Barnoon, P. Free convection of non-Newtonian nanofluid flow inside an eccentric annulus from the point of view of first-law and second-law of thermodynamics. J. Appl. Math. Mech. 2020, 101, e202000266. [CrossRef]

31. Barnoon, P. Numerical assessment of heat transfer and mixing quality of a hybrid nanofluid in a microchannel equipped with a dual mixer. Int. J. 2021, 12, 100111. [CrossRef] 
32. Barnoon, P.; Ashkiyan, M.; Toghraie, D. Embedding multiple conical vanes inside a circular porous channel filled by two-phase nanofluid to improve thermal performance considering entropy generation. Int. Commun. Heat Mass Transf. 2021, $124,105209$. [CrossRef]

33. Asogwa, K.; Mebarek-Oudina, F.; Animasaun, I. Comparative investigation of Water-based $\mathrm{Al}_{2} \mathrm{O}_{3}$ Nanoparticles through Waterbased $\mathrm{CuO}$ Nanoparticles over an Exponentially Accelerated Radiative Riga Plate Surface via Heat Transport. Arab. J. Sci. Eng. 2022. [CrossRef]

34. Barnoon, P.; Toghraie, D.; Karimipour, A. Application of rotating circular obstacles in improving ferrofluid heat transfer in an enclosure saturated with porous medium subjected to a magnetic field. J. Therm. Anal. Calorim. 2021, 145, 3301-3323. [CrossRef]

35. Khan, M.R.; Mao, S.; Deebani, W.; Elsiddieg, A.M.A. Numerical analysis of heat transfer and friction drag relating to the effect of Joule heating, viscous dissipation and heat generation/absorption in aligned MHD slip flow of a nanofluid. Int. Commun. Heat Mass Transf. 2022, 131, 105843. [CrossRef]

36. Warke, A.S.; Ramesh, K.; Mebarek-Oudina, F.; Abidi, A. Numerical Investigation of Nonlinear Radiation with Magnetomicropolar Stagnation Point Flow past a Heated Stretching Sheet. J. Therm. Anal. Calorim. 2021, 135, 533-549. [CrossRef]

37. Ravnik, J.; Škerget, L.; Yeigh, B. Nanofluid natural convection around a cylinder by BEM. WIT Trans. Model. Simul. 2015, 61, 261-271.

38. Ishak, M.S.; Alsabery, A.I.; Hashim, I.; Chamkha, A.J. Entropy production and mixed convection within trapezoidal cavity having nanofluids and localised solid cylinder. Sci. Rep. 2021, 11, 14700. [CrossRef] [PubMed]

39. Mebarek-Oudina, F.; Fares, R.; Aissa, A.; Lewis, R.W.; Abu-Hamdeh, N. Entropy and convection effect on magnetized hybrid nano-liquid flow inside a trapezoidal cavity with zigzagged wall. Int. Commun. Heat Mass Transf. 2021, 125, 105279. [CrossRef]

40. Mahmoudi, A.; Pop, I.; Shahi, M. Effect of magnetic field on natural convection in a triangular enclosure filled with nanofluid. Int J. Therm. Sci. 2012, 59, 126-140. [CrossRef]

41. Majdi, H.S.; Abed, A.M.; Habeeb, L.J. Mixed Convection Heat Transfer of Cuo- $\mathrm{H}_{2} \mathrm{O}$ Nanofluid in A Triangular Lid-Driven Cavity With Circular Inner Body. J. Mech. Eng. Res. Dev. 2021, 44, 164-175.

42. Wang, Y.-F.; Xu, X.; Tian, T.; Fan, L.W.; Wang, W.L.; Yu, Z.T. Laminar mixed convection heat transfer of SiC-EG nanofluids in a triangular enclosure with a rotating inner cylinder: Simulations based on the measured thermal conductivity and viscosity. $J$. Zhejiang Univ. Sci. A 2015, 16, 478-490. [CrossRef]

43. Triveni, M.; Panua, R. Numerical analysis of natural convection in a triangular cavity with different configurations of hot wall Int. J. Heat Technol. 2017, 35, 19-24. [CrossRef]

44. Hussain, S.; Rahomey, M. Comparison of Natural Convection around a Circular Cylinder with Different Geometries of Cylinders inside a Square Enclosure Filled with Ag-Nanofluid Superposed Porous-Nanofluid Layers. J. Heat Transf. $2018,141,22501$. [CrossRef]

45. Ali, F.H.; Hamzah, H.K.; Abdulkadhim, A. Numerical study of mixed convection nanofluid in an annulus enclosure between outer rotating cylinder and inner corrugation cylinder. Heat Transf. Asian Res. 2018, 48, 343-360. [CrossRef]

46. Pushpa, B.V.; Sankar, M.; Mebarek-Oudina, F. Buoyant convective flow and heat dissipation of $\mathrm{Cu}-\mathrm{H}_{2} \mathrm{O}$ nanoliquids in an annulus through a thin baffle. J. Nanofluids 2021, 10, 292-304. [CrossRef]

47. Marzougui, S.; Mebarek-Oudina, F.; Magherbi, M.; Mchirgui, A. Entropy Generation and Heat transport of Cu-water Nanoliquid in Porous lid-driven Cavity through Magnetic Field. Int. J. Numer. Methods Heat Fluid Flow 2021. [CrossRef]

48. Swain, K.; Mahanthesh, B.; Mebarek-Oudina, F. Heat transport and stagnation-point flow of magnetized nanoliquid with variable thermal conductivity with Brownian moment and thermophoresis aspects. Heat Transf. 2021, 50, 754-764. [CrossRef]

49. Mebarek-Oudina, F.; Aissa, A.; Mahanthesh, B.; Oztop, H.F. Heat Transport of Magnetized Newtonian Nanoliquids in an Annular Space between Porous Vertical Cylinders with Discrete Heat Source. Int. Comm. Heat Mass Transf. 2020, 117, 104737. [CrossRef]

50. Mebarek-Oudina, F. Convective Heat Transfer of Titania Nanofluids of different base fluids in Cylindrical Annulus with discrete Heat Source. Heat Transf. Asian Res. 2019, 48, 135-147. [CrossRef]

51. Swain, K.; Mebarek-Oudina, F.; Abo-Dahab, S.M. Influence of MWCNT/ $\mathrm{Fe}_{3} \mathrm{O}_{4}$ hybrid-nanoparticles on an exponentially porous shrinking sheet with chemical reaction and slip boundary conditions. J. Therm. Anal. Calorim. 2022, 147, 1561-1570. [CrossRef]

52. Abood, F.A.; Ismael, A.M. Steady Laminar Natural Convection Heat Transfer inside Air- Filled Horizontal Triangular Enclosure Containing Three Cylindrical Rods. BasrahJ. Eng. 2011, 65-79.

53. Das, D.; Basak, T. Analysis of entropy generation during natural convection in discretely heated porous square and triangular enclosures. Numer. Heat Transf. Part A Appl. 2017, 71, 979-1003. [CrossRef]

54. Djebali, R.; Mebarek-Oudina, F.; Choudhari, R. Similarity solution analysis of dynamic and thermal boundary layers: Further formulation along a vertical flat plate. Physica Scripta 2021, 96, 85206. [CrossRef]

55. Lei, Y.; Chen, Z.; Shi, J. Analysis of Condensation Heat Transfer Performance in Curved Triangle Microchannels Based on the Volume of Fluid Method. Microgravity Sci. Technol. 2017, 29, 433-443. [CrossRef]

56. Qi, C.; Liu, M.; Tang, J. Influence of triangle tube structure with twisted tape on the thermo-hydraulic performance of nanofluids in heat-exchange system based on thermal and exergy efficiency. Energy Convers. Manag. 2019, 192, 243-268. [CrossRef]

57. Gothäll, H. How to Inspect Your Mesh in COMSOL Multiphysics @ ${ }^{\circledR}$. Available online: https://www.comsol.com/blogs/howtoinspect-your-mesh-in-comsol-multiphysics / (accessed on 10 January 2021). 
58. Abed, M.; Aissa, A.; Mebarek-Oudina, F.; Jamshed, W.; Ahmed, W.; Ali, H.M.; Rashad, A.M. Galerkin Finite Element Analysis of Thermal Aspects of $\mathrm{Fe}_{3} \mathrm{O}_{4}$-MWCNT/Water Hybrid Nanofluid Filled in Wavy Enclosure with Uniform Magnetic Field Effect. Int. Commun. Heat Mass Transf. 2021, 126, 105461. [CrossRef]

59. Kadhim, H.T.; Jabbar, F.A.; Rona, A. $\mathrm{Cu}-\mathrm{Al}_{2} \mathrm{O}_{3}$ hybrid nanofluid natural convection in an inclined enclosure with wavy walls partially layered by porous medium. Int. J. Mech. Sci. 2020, 186, 105889. [CrossRef]

60. Nield, D.A.; Bejan, A. Convection in Porous Media; Springer: New York, NY, USA, 2017.

61. Yuanqing, W.; Jisheng, K.; Shuyu, S.; Yu-Shu, W. Thermodynamically consistent Darcy-Brinkman-Forchheimer framework in matrix acidization. Oil Gas Sci. Technol.-Rev. Energ. Nouv. 2021, 76, 8.

62. Varol, Y.; Avci, E.; Koca, A.; Oztop, H.F. Prediction of flow fields and temperature distributions due to natural convection in a triangular enclosure using Adaptive-Network-Based Fuzzy Inference System (ANFIS) and Artificial Neural Network (ANN). Int. Commun. Heat Mass Transf. 2007, 34, 887-896. [CrossRef]

63. Ikram, M.D.; Asjad, M.I.; Akgül, A.; Baleanu, D. Effects of hybrid nanofluid on novel fractional model of heat transfer flow between two parallel plates. Alex. Eng. J. 2021, 60, 3593-3604. [CrossRef]

64. Garud, K.S.; Lee, M.-Y. Numerical Investigations on Heat Transfer Characteristics of Single Particle and Hybrid Nanofluids in Uniformly Heated Tube. Symmetry 2021, 13, 876. [CrossRef]

65. Okello, J.A.; Mutuku, W.; Oyem, A. Analysis of Ethylene Glycol (EG)-based ((Cu- $\left.\left.\mathrm{Al}_{2} \mathrm{O}_{3}\right),\left(\mathrm{Cu}-\mathrm{TiO}_{2}\right),\left(\mathrm{TiO}_{2}-\mathrm{Al}_{2} \mathrm{O}_{3}\right)\right) \mathrm{Hybrid}$ Nanofluids for Optimal Car Radiator Coolant. J. Eng. Res. Rep. 2020, 17, 34-50. [CrossRef]

66. Ferhi, M.; Djebali, R.; Mebarek-Oudina, F.; H. Abu-Hamdeh, N.; Abboudi, S. MHD free convection through entropy generation analysis of eco-friendly nanoliquid in a divided L-shaped heat exchanger with LBM simulation. J. Nanofluids 2022, 11, 99-112.

67. Monaledi, R.L.; Makinde, O.D. Entropy generation analysis in a microchannel Poiseuille flows of nanofluid with nanoparticles injection and variable properties. J. Therm. Anal. Calorim. 2021, 143, 1855-1865. [CrossRef]

68. Zheng, J.; Zhang, L.; Yu, H.; Wang, Y.; Zhao, T. Study on natural convection heat transfer in a closed cavity with hot and cold tubes. Sci. Prog. 2021, 104, 965. [CrossRef] [PubMed] 